\title{
MicroRNA-1271 inhibits cellular proliferation of hepatocellular carcinoma
}

\author{
ANDONG QIN ${ }^{1}$, JIEHUA ZHU ${ }^{2}$, XINGXIANG LIU ${ }^{1}$, DONGXIAO ZENG ${ }^{1}$, MAOLIN GU $^{1}$ and $\mathrm{CHUN} \mathrm{LV}^{1}$ \\ ${ }^{1}$ Institute of Liver Disease, The Fourth Hospital of Huai'an, Huaian, Jiangsu 223002; ${ }^{2}$ Department of Laboratory Medicine, \\ The Affiliated Hospital of Zunyi Medical College, Zunyi, Guizhou 563000, P.R. China
}

Received September 13, 2015; Accepted February 13, 2017

DOI: $10.3892 / \mathrm{ol} .2017 .7052$

\begin{abstract}
Hepatocellular carcinoma (HCC) is one of the most common causes of cancer-associated mortality worldwide, particularly in China. MicroRNAs (miRs) serve important roles in the pathogenesis of HCC. The present study investigated the function of miR-1271 in HCC. The miR-1271 levels were analyzed by quantitative reverse transcription polymerase chain reaction. Cells growth was examined by MTT assay. Bioinformatics algorithms from TargetScanHuman were used to predict the target genes of miR-1271. The protein level was assayed by western blotting. miR-1271 demonstrated a lower expression level in HCC tissues. Upregulation of miR-1271 suppressed the growth of HepG-2 and Huh-7 cells and induced apoptosis of cells. Forkhead box Q1 (FOXQ1) was targeted by miR-1271. In conclusion, miR-1271 is a novel tumor suppressor that inhibits HCC proliferation and induces cellular apoptosis by targeting FOXQ1 in HCC. The results of the present study may provide a novel therapeutic target of $\mathrm{HCC}$.
\end{abstract}

\section{Introduction}

Hepatocellular carcinoma (HCC) accounts for $~ 80 \%$ of all liver cancer cases, and is one of the most common causes of cancer-associated mortality worldwide $(1,2)$. The prevalence rate of $\mathrm{HCC}$ in China is particularly high, but continues to increase in numerous western countries $(1,3)$. Despite HCC being was one of the first cancers to be linked epidemiologically to a definite risk factor, the underlying mechanisms of HCC pathogenesis remain unclear (4). The risk factors for HCC vary by location. In China, Hepatitis B or Hepatitis C virus infections are the main risk factors (5). The survival rate of patients with $\mathrm{HCC}$ has been extended due to progress in liver transplantation and other treatments; however, the insensitivity of chemotherapeutic drugs, cancer recurrence

Correspondence to: Dr Andong Qin, Institute of Liver Disease, The Fourth Hospital of Huaian City, 128 Yanan East Street, Huaian, Jiangsu 223002, P.R. China

E-mail: qinandongqin@126.com

Key words: hepatocellular carcinoma, microRNA-1271, cell growth, survival and metastasis continue to contribute to a poor prognosis (6). Thus, the identification of therapeutic targets and translation of molecular studies of HCC into clinical practice is urgently required.

MicroRNAs (miRNAs) are a class of small non-coding RNAs, which are 22 nucleotides in length (7-9). A number of miRNAs have been revealed to be involved in the pathogenesis of HCC (10-26). The roles of miR-1271 in numerous types of cancers have previously been investigated. For example, in gastric cancer, miR-1271 inhibited cell proliferation, invasion and epithelial-mesenchymal transition (EMT) by targeting forkhead box Q1 (FOXQ1) (27). Additionally, in oral squamous cell carcinoma, miR-1271 inhibited cell growth and metastasis by targeting anaplastic lymphoma receptor tyrosine kinase (28). In HCC, a previous study demonstrated that miR-96, miR-129-1-3p, miR-1291, miR-1303 and miR-1271 differentially regulated Glypican-3 (GPC3) expression levels in HCC cells and that the upregulation of GPC3 was associated with a concomitant downregulation of its repressor miR-1271 (29). However, the roles served by miR-1271 in HCC remain unclear.

The present study analyzed the expression level of miR-1271 in HCC tissues and determined the in vitro function of miR-1271. The aim of the study was to provide useful evidence and suggestions for additional investigations.

\section{Patients and methods}

Patients. A total of $22 \mathrm{HCC}$ tissue specimens were collected from the Institute of Liver Disease (The Fourth Hospital of Huaian City, Huaian, China). Tissue samples were immediately frozen in liquid nitrogen following isolation. Written informed consent was obtained from each patient prior to enrollment in the present study. The present study was approved by the Ethics Committee of The Fourth Hospital of Huaian. The specimens were processed using a hematoxylin and eosin staining protocol (30). Senior pathologists of The Fourth Hospital of Huaian (Huaian, China) evaluated the histological features of the specimens using LED microscopy at magnifications, x100 and x400 (DM300 Microscope, Leica Microsystems GmbH, Wetzlar, Germany).

Cell culture and antibodies. HCC Huh7 and HepG2 cells were purchased from the Cell Store of Shanghai Jiaotong University (Shanghai, China). The Huh7 cell line was maintained in 
RPMI-1640 medium supplemented with $10 \%$ fetal bovine serum (FBS; PAA Laboratories; GE Healthcare Life Sciences, Chalfont, UK). The human HCC HepG2 cell line was maintained in Dulbecco's modified Eagle's medium supplemented with 10\% FBS (PAA Laboratories; GE Healthcare Life Sciences). Antibodies specific to FOXQ1 (Anti-FOXQ1 antibody; cat. no., ab51340, working concentration: $2.5 \mu \mathrm{g} / \mathrm{ml}$ ) and $\beta$-actin (Anti- $\beta$-Actin antibody; cat. no., ab8226, working concentration: $0.05 \mu \mathrm{g} / \mathrm{ml}$ ) were supplied by Abcam (Cambridge, UK).

Reverse transcription-quantitative polymerase chain reaction (RT-qPCR). Total RNA was isolated using TRIzol ${ }^{\circledR}$ reagent (Invitrogen; Thermo Fisher Scientific, Inc., Waltham, MA, USA), was transcribed to cDNA using an EasyScript First-Strand cDNA Synthesis SuperMix kit (TransGen Biotech, Inc., Beijing, China) according to the manufacturer's protocol. The qPCR was carried out to detect the expression of miR-1271 and FOXQ1 mRNA by using SYBR-Green qPCR SuperMix-UDG with ROX (Invitrogen; Thermo Fisher Scientific, Inc.). The mRNA and miRNA primers were synthesized by Shanghai Genepharma Co. Ltd. (Shanghai, China). U6 and GAPDH were used as the references for detecting the expression of miR-1271 or FOXQ1, respectively. The primers used were as follows: miR-1271-forward (F), 5'-CAGCAC TTGGCACCTAGCA-3', miR-1271-reverse (R), 5'-TATGGT TGTTCTCCTCTCTGTCTC-3'; FOXQ1-F, 5'-GTGATTTCT TGCTATTGACCGATG-3', FOXQ1-R, 5'-GCCCAAGGA GACCACAGTTAGA-3'; U6-F, 5'-AGAGCCTGTGGTGTC CG-3', U6-R, 5'-CATCTTCAAAGCACTTCCCT-3'; and GAPDH-F, 5'-CATCACCATCTTCCAGGAGCG-3', GAPDH-R, 5'-TGACCTTGCCCACAGCCTTG-3'. Relative expression levels were calculated by the $2^{-\Delta \Delta \mathrm{Ct}}$ method (31-33). This experiment was repeated at least three times.

miR mimics and miR-antisense-oligonucleotides (AOS). miR-1271 mimics, miR-1271 antisense oligonucleotides and the negative control (NC) were purchased from Qiagen, Inc. (Valencia, CA, USA). miR-ASOs, miR mimics and the respective $\mathrm{NC}$ were transfected into cells at a concentration of $50 \mathrm{nM}$ using Lipofectamine ${ }^{\circledR} 2000$ transfection reagent (Invitrogen; Thermo Fisher Scientific, Inc.) at $37^{\circ} \mathrm{C}$ for $30 \mathrm{~min}$, according to the manufacturer's protocol. After transfection, the cells were maintained at $37^{\circ} \mathrm{C}$ for $48 \mathrm{~h}$ for additional experiments.

MTT assays. After $24 \mathrm{~h}$ of transfection of miR-1271 mimics and anti-miR-940,MDA-MB-231 and BT-549 cells (5x10³/well) were seeded into 96-well plates. Then, MTT experiments were performed as described previously (34).

Apoptosis assay for flow cytometry. Huh7 and HepG2 cells were seeded at a density of $0.3 \times 10^{6}$ overnight, then these cells were harvested and washed with PBS three times. The Fc receptor was blocked by $3 \%$ fetal bovine albumin at room temperature for 30 min. Cells were stained with Anti-Annexin V antibody (1:500, cat. no., ab63556; Abcam) at room temperature for $20 \mathrm{~min}$.

Bioinformatics methods. The miR-1271 targets predicted by algorithms were acquired from the Target Scan Human database (http://www.targetscan.org/vert_61/) (35-38).
FOXQ1 3'untranslated region (UTR) reporter analysis. The reporter genes analysis was performed by Chengdu Technology \& Market Co., Ltd. (Chengdu, China). Briefly, the 3'UTR of FOXQ1 was amplified and cloned into the downstream FOXQ1 3'UTR reporter plasmids (pRL-FOXQ1), using the following primers: FOXQ1-3'UTR-HF, 5'-AATTCTAGGCGATCGCTCGAGGACTACTGTTTGGG GTTTCTGG-3'; FOXQ1-3'UTR-HR, 5'-GCGGCCGCTCTAG GTTTAAACACACTTGCTTTCAAGGCAGTGG-3'. The thermocycler conditions were as follows: $95^{\circ} \mathrm{C}$ for $3 \mathrm{~min}$, then $95^{\circ} \mathrm{C}$ for $30 \mathrm{sec}, 53^{\circ} \mathrm{C}$ for $30 \mathrm{sec}$ and $72^{\circ} \mathrm{C}$ for $30 \mathrm{sec}$ for 28 cycles, followed by $72^{\circ} \mathrm{C}$ for $2 \mathrm{~min}$. Mutants of FOXQ1 $3^{\prime}$ UTR were generated using the Site-Directed Mutagenesis kit (Shanghai Shengong Biotechnology Company, Shanghai, China). For the luciferase reporter assay, the cells were co-transfected with miR-1271 mimics, control and reporter plasmid or the mutant $3^{\prime} \mathrm{UTR}$, together with the controls using Lipofectamine ${ }^{\circledR} 2000$ at $37^{\circ} \mathrm{C}$ for $30 \mathrm{~min}$. At $48 \mathrm{~h}$ following transfection, cells were analyzed using the Dual Luciferase reporter assay system (Promega Corporation, Madison, WI, USA) as described previously (39).

Western blot analysis. Cells $\left(5 \times 10^{6}\right.$ cells) were lysed using $50 \mu \mathrm{l}$ M-PER protein extraction reagent (Pierce; Thermo Fisher Scientific, Inc.) supplemented with $10 \mu \mathrm{l}$ protease inhibitor cocktail (EMD Millipore, Billerica, MA, USA) on ice for $45 \mathrm{~min}$ (40). Protein quantification was evaluated using a BCA assay and absorbance at $280 \mathrm{~nm}$ (Pierce; Thermo Fisher Scientific, Inc.). Protein $(20 \mu \mathrm{g})$ was separated using $10 \%$ SDS-PAGE gels, then electrophoretically transferred onto nitrocellulose membranes (Bio-Rad Laboratories, Inc., Hercules, CA, USA). The membranes were blocked with $5 \%$ milk/TBS Tween-20 at $4^{\circ} \mathrm{C}$ overnight, and then incubated with antibodies specific to FOXQ1 (Anti-FOXQ1 antibody; cat. no., ab51340, working concentration, $2.5 \mu \mathrm{g} / \mathrm{ml}$ ) at $4^{\circ} \mathrm{C}$ overnight, followed by incubation with a horseradish peroxidase-conjugated secondary antibody (goat anti-rabbit IgG H\&L, cat. no., ab6721, 1:1,000) at room temperature for 2 h (Abcam, Cambridge, United Kingdom). The membranes were washed with TBS three times and then images were visualized by chemiluminescence and LabWorks Image Acquisition and Analysis Software 2 (UVP LLC, Upland, CA, USA).

Statistical analysis. Statistical analyses were conducted using SPSS version 18 (SPSS, Inc., Chicago, IL, USA). Data are presented as the mean \pm standard deviation from three experimental repeats. Two-tailed Student's t-test was used to analyze the difference between two groups. One-way ANOVA was used to analyze the difference between three groups. Multiple comparison between the groups was performed using the Student Newman Keuls method. The Wilcoxon matched-pairs signed rank test was used to determine the difference between the expression level of miR-1271 in HCC tissues and the matched controls. Kaplan-Meier analysis was used to evaluate the overall survival rate of patients with HCC according to the expression level of miR-1271 in HCC tissues. The correlation analysis was performed by two-tailed Pearson's correlation coefficient analysis. $\mathrm{P}<0.05$ was considered to indicate a statistically significant difference. 

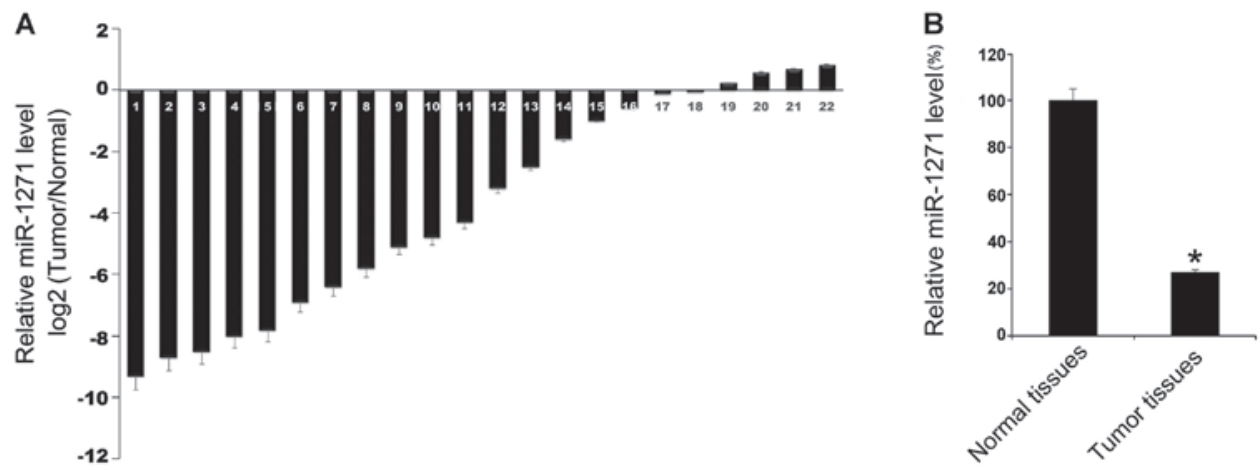

Figure 1. Lower expression level of miR-1271 in HCC tissues. A total of 22 pairs of HCC tissues and corresponding tumor-adjacent normal tissues were collected from The Fourth Hospital of Huaian City (Jiangsu, China). (A) The miR-1271 expression levels were analyzed by reverse transcription-quantitative polymerase chain reaction. The difference in expression level of miR-1271 between tumor tissues and matched normal tissues was determined. (B) The mean miR-1271 expression level in the HCC tissues and the corresponding tumor-adjacent normal tissues. Data are expressed as the mean \pm standard deviation of three separate experiments. "P<0.05. miR, microRNA; HCC, hepatocellular carcinoma.

A
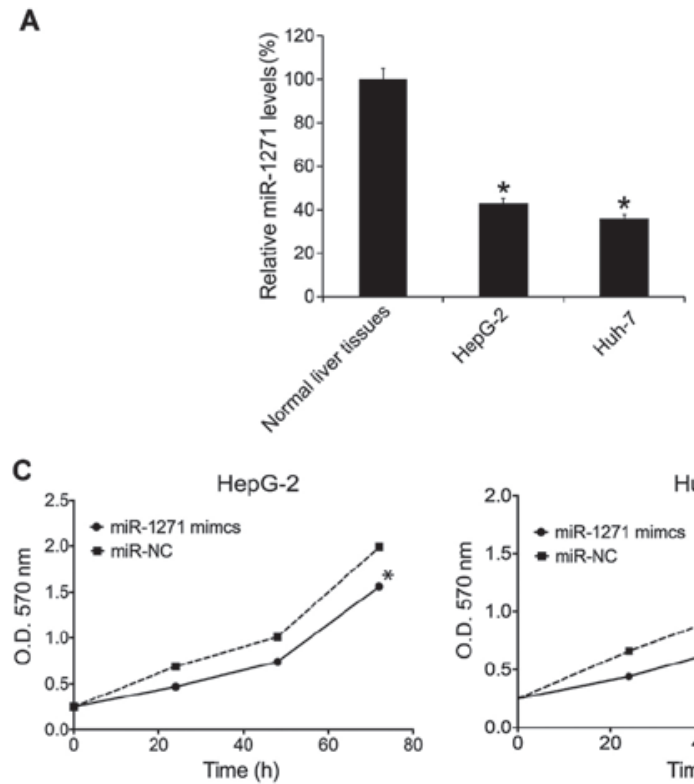

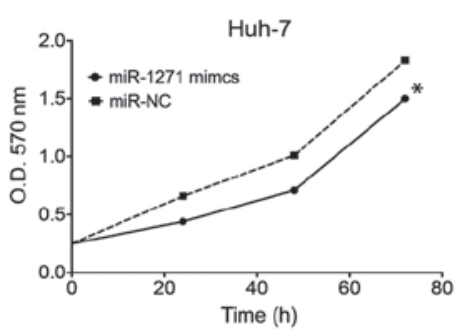

B

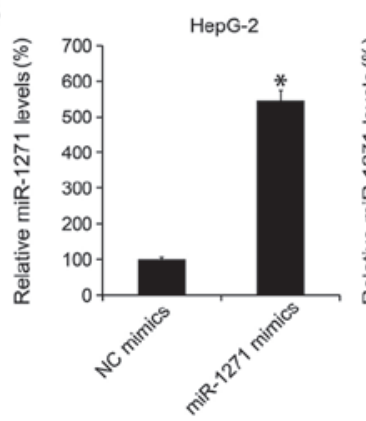

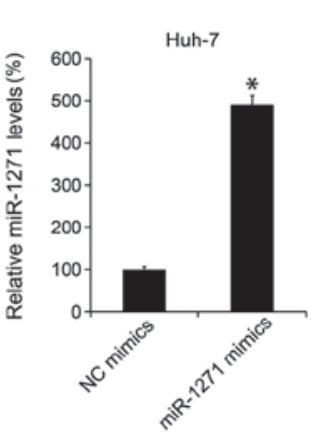

D

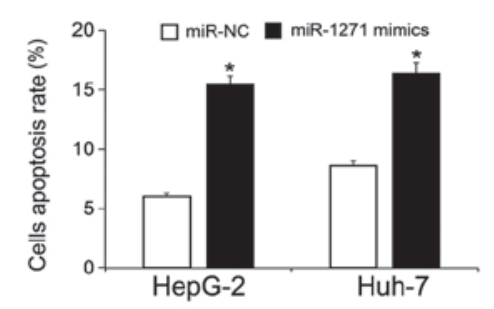

Figure 2. Transfection with miR-1271 mimics inhibited HepG-2 and Huh-7 cell growth and induced apoptosis. The total RNA of normal liver tissues, HepG2 and Huh-7 were extracted. The miR-1271 expression levels were analyzed by RT-qPCR analysis. (A) The miR-1271 expression levels of normal liver tissues were treated as $100 \%$. Following a $48 \mathrm{~h}$ miR-1271 mimic transfection, the expression levels of miR-1271 in HepG-2 and Huh-7 cells were examined by RT-qPCR. (B) The expression level of miR-1271 in the miR-NC transfected group was deliberately treated as 100\%. (C) The rate of cell growth was evaluated by MTT analysis at the indicated time point. (D) Following miR-1271 mimic transfection, cell apoptosis was examined by apoptosis FACS analysis. All data are presented as the mean \pm standard deviation of three separate experiments. " $\mathrm{P}<0.05$. miR, microRNA; HCC, hepatocellular carcinoma; RT-qPCR, reverse transcription-quantitative polymerase chain reaction; NC, negative control; OD, optical density.

\section{Results}

miR-1271 is frequently downregulated in HCC tissues. Initially, miR-1271 expression levels in tumor tissues and the matched adjacent normal tissues of 22 patients with HCC were evaluated by RT-qPCR. The results indicated that in 22 patients with HCC, compared with the matched non-tumorous tissues, the majority of HCC tissues exhibited lower miR-1271 expression levels compared with the corresponding tumor-adjacent normal tissues (Fig. 1A). Furthermore, the $22 \mathrm{HCC}$ tissues demonstrated a lower mean expression level of miR-1271 compared with in normal tissues (Fig. 1B). These results indicated that miR-1271 may serve an important role in HCC.
Overexpression of miR-1271 inhibited cell growth and promoted apoptosis of cells. The miR-1271 expression levels in HCC cell lines, HepG-2 and Huh-7, were analyzed by RT-qPCR. The results indicated that there were lower expression levels of miR-1271 in HepG-2 and Huh-7 cells compared with normal liver tissue (Fig. 2A). The present study subsequently overexpressed miR-1271 by performing miR-1271 mimic transfection. Following $48 \mathrm{~h}$, the miR-1271 expression levels in HepG-2 and Huh-7 cells were evaluated by RT-qPCR. It was revealed that miR-1271 mimic transfection upregulated miR-1271 levels in HepG-2 and Huh-7 cells (Fig. 2B). Following the transfection, cellular proliferation rate was determined by MTT analysis. The results suggested that transfection of miR-1271 mimics inhibited HepG-2 and Huh-7 cell growth 

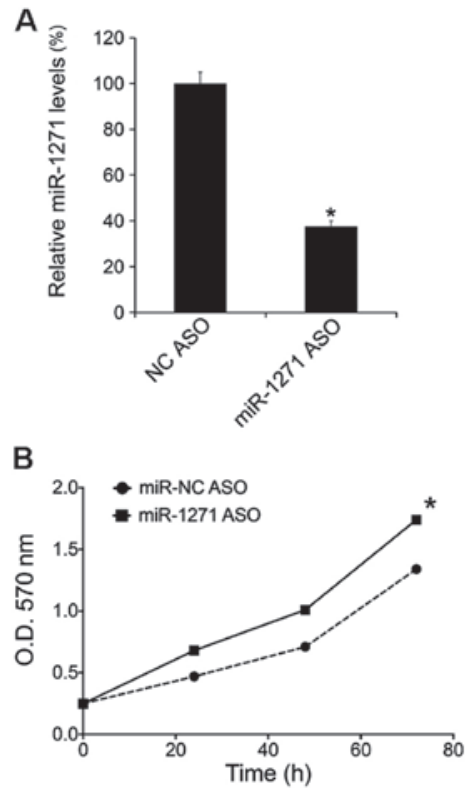
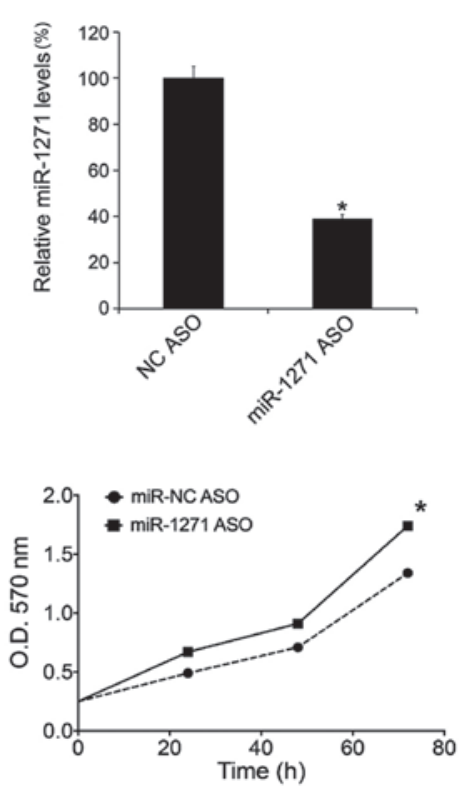

C

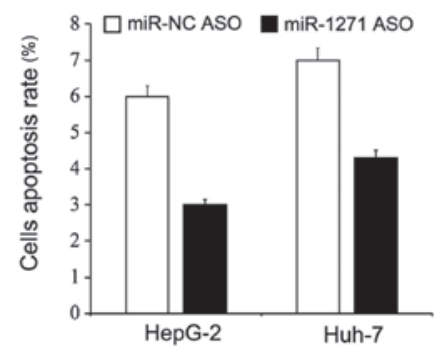

Figure 3. Transfection with miR-1271 ASO promoted HepG-2 and Huh-7 growth and inhibited apoptosis. Following miR-1271 ASO transfection, the expression levels of miR-1271 in HepG-2 and Huh-7 cells were evaluated by reverse transcription-quantitative polymerase chain reaction. (A) The expression level of miR-1271 in the miR-NC ASO treated group was deliberately treated as 100\%. (B) The rate of cell growth was determined by MTT analysis at the indicated time point. (C) Following miR-1271 mimic transfection, cell apoptosis was examined by apoptosis FACS analysis. All data are presented as the mean \pm standard deviation of three separate experiments. "P<0.05. miR, microRNA; ASO, antisense oligonucleotides; NC, negative control; OD, optical density.

A

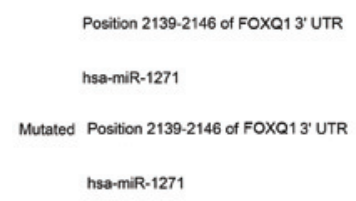

C

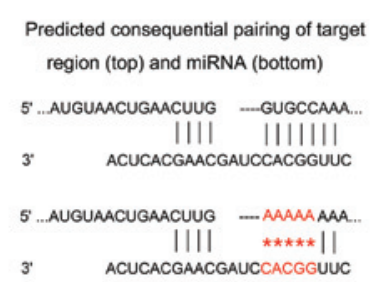

Predicted consequential pairing of target

B

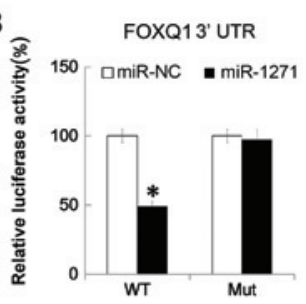

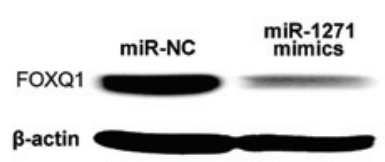

D

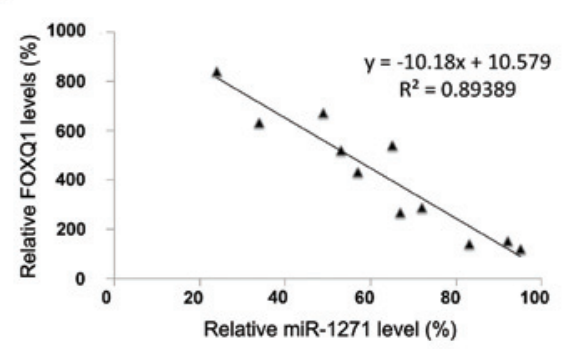

Figure 4. FOXQ1 was targeted by miR-1271. (A) TargetScanHuman (www.targetscan. org) demonstrated that FOXQ1 was a direct target of miR-1271. (B) HepG-2 cells were co-transfected with miR-1271 mimics, the control and reporter plasmid or the Mut 3'UTR, together with the controls. (C) HepG-2 cells were transfected with miR-1271 mimics. Subsequent to $48 \mathrm{~h}$, western blot analysis was performed to determine the expression level of FOXQ1 protein. (D) FOXQ1 mRNA expression levels in $11 \mathrm{HCC}$ tissues were examined by reverse transcription-quantitative polymerase chain reaction. The correlation between FOXQ1 mRNA and miR-1271 expression levels were determined by two-tailed Pearson's correlation coefficient analysis. All data are presented as the mean \pm standard deviation of three separate experiments. "P<0.05. FOXQ1, Forkhead box Q1; miR, microRNA; 3'UTR, 3'untraslated region; HCC, hepatocellular carcinoma; NC, negative control; WT, wild type; Mut, mutant. 
(Fig. 2C). A total of $48 \mathrm{~h}$ subsequent to transfection, cells were prepared for apoptosis analysis and it was demonstrated that transfection of miR-1271 mimics induced an increase in the levels of cellular apoptosis (Fig. 2D).

Downregulation of miR-1271 promoted cell growth and inhibited apoptosis. The present study downregulated miR-1271 expression levels by transfection of miR-1271 ASO. Following $48 \mathrm{~h}$, the miR-1271 expression levels in HepG-2 and Huh-7 cells were determined by RT-qPCR and it was revealed that miR-1271 ASO transfection downregulated the miR-1271 levels in HepG-2 and Huh-7 cells (Fig. 3A). Following the transfection, cellular proliferation rate was evaluated by MTT analysis. The present study demonstrated that transfection of miR-1271 mimics promoted HepG-2 and Huh-7 cell growth (Fig. 3B). Following a $48 \mathrm{~h}$ transfection, cells were prepared for apoptosis analysis and the results revealed that transfection of miR-1271 mimics inhibited apoptosis (Fig. 3C).

miR-1271 targets FOXQ1 in HCC cells. In order to investigate mechanism underlying miR-1271 in HCC, the present study predicted the potential target genes of miR-1271 using bioinformatics algorithms. Numerous genes were predicted (data not shown), including FOXQ1. FOXQ1 is a member of the forkhead transcription factor family (41). A previous study revealed that FOXQ1 is a modulator of TWIST-1 mediated metastatic phenotypes and a biomarker of metastasis (42). FOXQ1 served a key role in regulating EMT and aggressiveness of human cancer (43). Therefore, FOXQ1 was selected for additional investigation. The binding sites with miR-1271 and the mutant sequence were listed (Fig. 4A). Following the construction of luciferase reporter plasmids with 3'UTR of FOXQ1 or mutant, miR-1271 mimics and reporter plasmids were co-transfected into HepG-2 cells: This revealed that overexpression of miR-1271 reduced the luciferase activity of wild type 3'UTR reporter; however, in the mutated 3'UTR reporter, miR-1271 demonstrated less effect (Fig. 4B). Next, HepG-2 cells were transfected with miR-1271 mimics. After $48 \mathrm{~h}$, western blot analysis was performed to determine the expression level of FOXQ1 protein, and it was identified that the transfection of miR-1271 mimics inhibited the FOXQ1 protein expression in HepG-2 cells (Fig. 4C). Finally, the FOXQ1 mRNA expression levels in $11 \mathrm{HCC}$ tissues were examined by PCR. It was demonstrated that the FOXQ1 mRNA expression levels and miR-1271 expression levels were negatively correlated (Fig. 4D).

\section{Discussion}

The present study determined the function of miR-1271 by alteration of miR-1271 expression levels in HCC cells HCC tissues revealed a lower expression level of miR-1271. Overexpression of miR-1271 inhibited cell growth and promoted apoptosis, and downregulation of miR-1271 promoted cell growth and inhibited apoptosis. miR-1271 targeted FOXQ1. The downregulation of miR-1271 in HCC has been demonstrated in a previous study (29). The results of the present study revealed a clear role of miR-1271 in HCC.

The present study demonstrated that FOXQ1 was targeted by miR-1271. It has previously been revealed that FOXQ1 is overexpressed in various types of human cancer, including colorectal (44), breast (45) and lung cancer (45) and HCC $(46,47)$. Notably, high FOXQ1 expression levels were independent prognostic factors of HCC (46). As FOXQI was targeted by miR-1271, the present study suggested that miR-1271 may be a prognostic factor of HCC.

In addition, FOXQ1 has been reported to be a target of TGF- $\beta$ signaling in breast cancer (48) and a novel target of the Wnt- $\beta$-catenin signaling pathway in colorectal cancer (49). miR-124 suppressed tumor growth and metastasis by targeting FOXQ1 in nasopharyngeal cancer (50). An additional previous study suggested that there was a double-negative feedback loop between miR-422a and its targeted gene, FOXQ1, in HCC (51). To the best of our knowledge, the present study demonstrated for the first time that FOXQ1 was directly downregulated by miR-1271 in HCC.

In conclusion, the present study identified miR-1271 as a novel tumor suppressor that inhibits HCC cell growth and induces cellular apoptosis by targeting FOXQ1 in HCC. These results indicated that miR-1271 could be potential molecular target for additional investigation.

\section{Acknowledgements}

The present study was supported by the Key Project of Research and Development of Huai'an (grant no., HAS2014007)

\section{References}

1. Siegel RL, Miller KD and Jemal A: Cancer statistics, 2015. CA Cancer J Clin 65: 5-29, 2015.

2. Torre LA, Bray F, Siegel RL, Ferlay J, Lortet-Tieulent J and Jemal A: Global cancer statistics, 2012. CA Cancer J Clin 65: 87-108, 2015.

3. Venook AP, Papandreou C, Furuse J and de Guevara LL: The incidence and epidemiology of hepatocellular carcinoma: A global and regional perspective. Oncologist 15 (Suppl 4): S5-S13, 2010.

4. Beasley RP: Hepatitis B virus. The major etiology of hepatocellular carcinoma. Cancer 61: 1942-1956, 1988.

5. Song P, Feng X, Zhang K, Song T, Ma K, Kokudo N, Dong J, Yao $\mathrm{L}$ and Tang W: Screening for and surveillance of high-risk patients with HBV-related chronic liver disease: Promoting the early detection of hepatocellular carcinoma in China. Biosci Trends 7: 1-6, 2013.

6. Karaman B, Battal B, Sari S and Verim S: Hepatocellular carcinoma review: Current treatment, and evidence-based medicine. World J Gastroenterol 20: 18059-18060, 2014.

7. Bartel DP: MicroRNAs: Genomics, biogenesis, mechanism, and function. Cell 116: 281-297, 2004.

8. Ambros V: The functions of animal microRNAs. Nature 431: 350-355, 2004.

9. He L and Hannon GJ: MicroRNAs: Small RNAs with a big role in gene regulation. Nat Rev Genet 5: 522-531, 2004.

10. Gramantieri L, Ferracin M, Fornari F, Veronese A, Sabbioni S, Liu CG, Calin GA, Giovannini C, Ferrazzi E, Grazi GL, et al: Cyclin G1 is a target of miR-122a, a microRNA frequently down-regulated in human hepatocellular carcinoma. Cancer Res 67: 6092-6099, 2007.

11. Budhu A, Jia HL, Forgues M, Liu CG, Goldstein D, Lam A, Zanetti KA, Ye QH, Qin LX, Croce CM, et al: Identification of metastasis-related microRNAs in hepatocellular carcinoma. Hepatology 47: 897-907, 2008.

12. Xu T, Zhu Y, Xiong Y, Ge YY, Yun JP and Zhuang SM: MicroRNA-195 suppresses tumorigenicity and regulates G1/S transition of human hepatocellular carcinoma cells. Hepatology 50: 113-121, 2009.

13. Su H, Yang JR, Xu T, Huang J, Xu L, Yuan Y and Zhuang SM: MicroRNA-101, down-regulated in hepatocellular carcinoma, promotes apoptosis and suppresses tumorigenicity. Cancer Res 69: 1135-1142, 2009. 
14. Murakami Y, Yasuda T, Saigo K, Urashima T, Toyoda H, Okanoue $\mathrm{T}$ and Shimotohno K: Comprehensive analysis of microRNA expression patterns in hepatocellular carcinoma and non-tumorous tissues. Oncogene 25: 2537-2545, 2006.

15. Braconi $C$ and Patel T: MicroRNA expression profiling: $A$ molecular tool for defining the phenotype of hepatocellular tumors. Hepatology 47: 1807-1809, 2008.

16. Murakami Y, Tamori A, Itami S, Tanahashi T, Toyoda $\mathrm{H}$, Tanaka M, Wu W, Brojigin N, Kaneoka Y, Maeda A, et al: The expression level of miR-18b in hepatocellular carcinoma is associated with the grade of malignancy and prognosis. BMC Cancer 13: 99, 2013.

17. Gramantieri L, Fornari F, Callegari E, Sabbioni S, Lanza G, Croce CM, Bolondi L and Negrini M: MicroRNA involvement in hepatocellular carcinoma. J Cell Mol Med 12: 2189-2204, 2008.

18. Wang B, Majumder S, Nuovo G, Kutay H, Volinia S, Patel T, Schmittgen TD, Croce C, Ghoshal K and Jacob ST: Role of microRNA-155 at early stages of hepatocarcinogenesis induced by choline-deficient and amino acid-defined diet in C57BL/6 mice. Hepatology 50: 1152-1161, 2009.

19. Coulouarn C, Factor VM, Andersen JB, Durkin ME and Thorgeirsson SS: Loss of miR-122 expression in liver cancer correlates with suppression of the hepatic phenotype and gain of metastatic properties. Oncogene 28: 3526-3536, 2009.

20. Ji J, Shi J, Budhu A, Yu Z, Forgues M, Roessler S, Ambs S, Chen Y, Meltzer PS, Croce CM, et al: MicroRNA expression, survival, and response to interferon in liver cancer. $\mathrm{N}$ Engl $\mathrm{J}$ Med 361: 1437-1447, 2009.

21. Ji J, Yamashita T, Budhu A, Forgues M, Jia HL, Li C, Deng C, Wauthier E, Reid LM, Ye QH, et al: Identification of microRNA-181 by genome-wide screening as a critical player in EpCAM-positive hepatic cancer stem cells. Hepatology 50 472-480, 2009

22. Ladeiro Y, Couchy G, Balabaud C, Bioulac-Sage P, Pelletier L, Rebouissou S and Zucman-Rossi J: MicroRNA profiling in hepatocellular tumors is associated with clinical features and oncogene/tumor suppressor gene mutations. Hepatology 47 1955-1963, 2008.

23. Song G, Sharma AD, Roll GR, Ng R, Lee AY, Blelloch RH, Frandsen NM and Willenbring H: MicroRNAs control hepatocyte proliferation during liver regeneration. Hepatology 51: $1735-1743,2010$

24. Ura S, Honda M, Yamashita T, Ueda T, Takatori H, Nishino R, Sunakozaka H, Sakai Y, Horimoto K and Kaneko S: Differential microRNA expression between hepatitis B and hepatitis C leading disease progression to hepatocellular carcinoma. Hepatology 49: 1098-1112, 2009

25. Wong TS, Liu XB, Wong BY, Ng RW, Yuen AP and Wei WI: Mature miR-184 as potential oncogenic microRNA of squamous cell carcinoma of tongue. Clin Cancer Res 14: 2588-2592, 2008

26. Wang Y, Lee AT, Ma JZ, Wang J, Ren J, Yang Y, Tantoso E, Li KB, Ooi LL, Tan P and Lee CG: Profiling microRNA expression in hepatocellular carcinoma reveals microRNA-224 up-regulation and apoptosis inhibitor-5 as a microRNA-224-specific target. J Biol Chem 283: 13205-13215, 2008.

27. Xiang XJ, Deng J, Liu YW, Wan LY, Feng M, Chen J and Xiong JP: MiR-1271 inhibits cell proliferation, invasion and EMT in gastric cancer by targeting FOXQ1. Cell Physiol Biochem 36: $1382-1394,2015$

28. Kong D, Zhang G, Ma H and Jiang G: miR-1271 inhibits OSCC cell growth and metastasis by targeting ALK. Neoplasma 62: $559-566,2015$

29. Maurel M, Jalvy S, Ladeiro Y, Combe C, Vachet L, Sagliocco F, Bioulac-Sage P, Pitard V, Jacquemin-Sablon H, Zucman-Rossi J, et al: A functional screening identifies five microRNAs controlling glypican-3: Role of miR-1271 down-regulation in hepatocellular carcinoma. Hepatology 57 195-204, 2013.

30. Fischer AH, Jacobson KA, Rose J and Zeller R: Hematoxylin and eosin staining of tissue and cell sections. CSH Protoc 2008: pdb. prot4986, 2008.

31. Li D, Liu X, Lin L, Hou J, Li N, Wang C, Wang P, Zhang Q, Zhang P, Zhou W, et al: MicroRNA-99a inhibits hepatocellular carcinoma growth and correlates with prognosis of patients with hepatocellular carcinoma. J Biol Chem 286: 36677-36685, 2011.
32. Song B, Zhang C, Li G, Jin G and Liu C: MiR-940 inhibited pancreatic ductal adenocarcinoma growth by targeting MyD88. Cell Physiol Biochem 35: 1167-1177, 2015.

33. Livak KJ and Schmittgen TD: Analysis of relative gene expression data using real-time quantitative PCR and the 2(-Delta Delta C(T)) method. Methods 25: 402-408, 2001.

34. Mosmann T: Rapid colorimetric assay for cellular growth and survival: Application to proliferation and cytotoxicity assays. J Immunol Methods 65: 55-63, 1983.

35. Lewis BP, Burge CB and Bartel DP: Conserved seed pairing, often flanked by adenosines, indicates that thousands of human genes are microRNA targets. Cell 120: 15-20, 2005.

36. Friedman RC, Farh KK, Burge CB and Bartel DP: Most mammalian mRNAs are conserved targets of microRNAs. Genome Res 19: 92-105, 2009.

37. Grimson A, Farh KK, Johnston WK, Garrett-Engele P, Lim LP and Bartel DP: MicroRNA targeting specificity in mammals: Determinants beyond seed pairing. Mol Cell 27: 91-105, 2007.

38. Garcia DM, Baek D, Shin C, Bell GW, Grimson A and Bartel DP: Weak seed-pairing stability and high target-site abundance decrease the proficiency of 1sy- 6 and other microRNAs. Nat Struct Mol Biol 18: 1139-1146, 2011.

39. Grentzmann G, Ingram JA, Kelly PJ, Gesteland RF and Atkins JF: A dual-luciferase reporter system for studying recoding signals. RNA 4: 479-486, 1998.

40. Zhang H, Cai X, Wang Y, Tang H, Tong D and Ji F: microRNA-143, down-regulated in osteosarcoma, promotes apoptosis and suppresses tumorigenicity by targeting Bcl-2. Oncol Rep 24: $1363-1369,2010$

41. Carlsson P and Mahlapuu M: Forkhead transcription factors: Key players in development and metabolism. Dev Biol 250: 1-23, 2002.

42. Abba M,Patil N, Rasheed K, Nelson LD, Mudduluru G, Leupold JH and Allgayer $\mathrm{H}$ : Unraveling the role of FOXQ1 in colorectal cancer metastasis. Mol Cancer Res 11: 1017-1028, 2013.

43. Qiao Y, Jiang X, Lee ST, Karuturi RK, Hooi SC and Yu Q FOXQ1 regulates epithelial-mesenchymal transition in human cancers. Cancer Res 71: 3076-3086, 2011.

44. Kaneda H, Arao T, Tanaka K, Tamura D, Aomatsu K, Kudo K, Sakai K, De Velasco MA, Matsumoto K, Fujita Y, et al: FOXQ1 is overexpressed in colorectal cancer and enhances tumorigenicity and tumor growth. Cancer Res 70: 2053-2063, 2010.

45. Feng J, Zhang X, Zhu H, Wang X, Ni S and Huang J: FoxQ1 overexpression influences poor prognosis in non-small cell lung cancer, associates with the phenomenon of EMT. PLoS One 7: e39937, 2012

46. Wang W, He S, Ji J, Huang J, Zhang S and Zhang Y: The prognostic significance of FOXQ1 oncogene overexpression in human hepatocellular carcinoma. Pathol Res Pract 209: 353-358, 2013.

47. Xia L, Huang W, Tian D, Zhang L, Qi X, Chen Z, Shang X, Nie Y and Wu K: Forkhead box Q1 promotes hepatocellular carcinoma metastasis by transactivating ZEB2 and VersicanV1 expression. Hepatology 59: 958-973, 2014.

48. Fan DM, Feng XS, Qi PW and Chen YW: Forkhead factor FOXQ1 promotes TGF-b1 expression and induces epithelial-mesenchymal transition. Mol Cell Biochem 397: 179-186, 2014.

49. Christensen J, Bentz S, Sengstag T, Shastri VP and Anderle P: FOXQ1, a novel target of the Wnt pathway and a new marker for activation of Wnt signaling in solid tumors. PLoS One 8: e60051, 2013.

50. Peng XH, Huang HR, Lu J, Liu X, Zhao FP, Zhang B, Lin SX, Wang L, Chen HH, Xu X, et al: MiR-124 suppresses tumor growth and metastasis by targeting Foxq1 in nasopharyngeal carcinoma. Mol Cancer 13: 186, 2014

51. Zhang J, Yang Y, Yang T, Yuan S, Wang R, Pan Z, Yang Y, Huang G, Gu F, Jiang B, et al: Double-negative feedback loop between microRNA-422a and forkhead box (FOX)G1/Q1/E1 regulates hepatocellular carcinoma tumor growth and metastasis. Hepatology 61: 561-573, 2015. 